\title{
El papel de la imaginación en La memoria, la historia, el olvido de Paul Ricœur
}

\author{
ESTEBAN LYTHGOE \\ Consejo Nacional de Investigaciones Científicas y Técnicas \\ estebanlythgoe@yahoo.com.ar
}

Resumen: Varios intérpretes han reconocido la importancia de la imaginación productiva en la obra de Ricœur, aunque la mayoría de ellos ha abocado sus investigaciones a las obras del filósofo francés de las décadas de los setenta y ochenta. En lo que sigue quisiera sostener que la imaginación también tiene un papel central en La memoria, la historia, el olvido. Mi hipótesis es que esta facultad articula los distintos momentos de esta obra, fundamentalmente los relacionados con la fenomenología de la memoria y la epistemología de la historia. Asimismo quisiera relativizar parcialmente la tesis de que a partir de Tiempo y narración Ricœur enfatiza el carácter sintético de la imaginación, mostrando que en la obra que abordaré hay una fuerte presencia de la función libre.

Palabras clave: Imaginación sintética, imaginación libre, reconocimiento, ideología, utopía

\begin{abstract}
Several interpreters have recognized the importance of productive imagination in Ricœur's work, but most of them have focused their research on his works of the seventies and eighties. I want to argue that imagination has also a central role in Memory, History, Forgetting. My hypothesis is that this notion articulates the different moments of the work, mainly those related to phenomenology of memory and epistemology of history. I also wish to relativize the argument that after Time and Narrative Ricœur emphasized synthetic imagination, by showing the presence of free imagination in Memory, History, Forgetting.
\end{abstract}

Palabras clave: Synthetic imagination, free imagination, recognition, ideology, utopia

\section{La imaginación productiva en la obra de Ricœur}

La problemática de la imaginación impregna la mayor parte de las investigaciones de Ricœur después de la década de los sesenta (Revault d'Allones 1986, p. 13). Como explica Richard Kearney,

mientras sus trabajos tempranos -en particular Libertad y naturaleza (1950) - se ajustaban a las convenciones descriptivas de la fenomenología eidética, la publicación de La simbología del mal en 1960 introdujo un modelo "hermenéutico" de análisis que abrió la posibilidad de una nueva apreciación del funcionamiento lingüístico de la imaginación. (Kearney 1998, pp. 134-135) 
Pese a la originalidad y a la extensión de la problemática de la imaginación, "en el trabajo publicado de Ricœur encontramos sólo referencias dispersas sobre este tópico y ningún desarrollo amplio sobre este tema aparentemente tan central para su pensamiento" (Taylor 2006, p. 93). Una posible explicación de esta ausencia podría ser que al filósofo le interesaba la función de la imaginación y no sus contenidos, por lo que su tratamiento se subordinó a otras temáticas afectadas por esa funcionalidad de la imaginación.

Diversos intérpretes vinculan el paso de Ricœur de un pensamiento afín con la fenomenología a una filosofía hermenéutica con la adopción del concepto de imaginación productiva en clave kantiana. La mayor parte de la tradición filosófica occidental permaneció aferrada a esta concepción reproductiva de la imaginación; Kant, por su parte, propugna una imaginación productiva. Siguiendo al pensador de Königsberg, Ricœur dejó de caracterizar la imaginación en términos visuales para definirla a partir del lenguaje. El modelo semántico de la imaginación supuso grandes cambios en el papel que podía cumplir en la filosofía. Deja de considerarse una facultad menor, subordinada y engañadora, cuyos productos son meramente residuos casi materiales de la percepción (como creía el empirismo) o la neutralización o negación de la percepción (como la fenomenología tendía a pensar). El tratamiento Ricœuriano de la imaginación dejó de enfocarse en los productos de esta facultad, inclinándose, en su lugar, a indagar sobre su función como capacidad creativa y disruptiva. ${ }^{1}$

La mayor parte de las consideraciones en torno a la imaginación se encuentran en los textos de mediados de la década de los setenta y principios de los ochenta, entre los que se encuentran La metáfora viva, Del texto a la acción e Ideología y utopía. Durante la década de los setenta, Ricœur también impartió en Chicago unos cursos acerca de esa problemática que todavía están en proceso de edición. Justamente la mayor parte de los estudios académicos sobre la imaginación en este filósofo se basa en esas obras. Incluso algunos especialistas han sostenido que, más allá de la afirmación del propio Ricœur de que La metáfora viva y Tiempo y narración son obras gemelas, ${ }^{2}$ hubo una ruptura entre ambos trabajos que incidió en el tratamiento de la imaginación. ${ }^{3}$ Charles Tay-

${ }^{1}$ Cfr. Kearney 1998, p. 140: "Ricœur claims that what matters in imagination is less the content than the function of images."

${ }^{2}$ Cfr. Ricœur 1995, p. 31: "La metáfora viva y Tiempo y narración son dos obras gemelas. Publicadas consecutivamente, fueron, sin embargo, concebidas juntas."

${ }^{3}$ Cfr. Taylor 2013, p. 127: "Minha hesitante tese é que, na transição entre o texto sobre a imaginação e Tempo e narrativa, a ênfase que Ricœur conferiu ao tema da 
lor, editor de los cursos sobre la imaginación mencionados, sostiene que en dichos cursos Ricœur había enfatizado la diferencia entre dos sentidos de la imaginación productiva. ${ }^{4} \mathrm{El}$ primero, inspirado en el análisis de Kant en la Crítica a la razón pura, subraya el carácter de esquema de la imaginación, es decir, la capacidad sintética de establecer una conexión entre una intuición y un concepto; el segundo, en cambio, ligado con la Crítica del juicio, resalta la libertad de la imaginación respecto de las reglas. En opinión de Taylor, mientras que en sus obras de los setenta y principios de los ochenta, como es el caso de Ideología y utopía, Ricœur enfatizaba este segundo uso de la imaginación, a partir de Tiempo y narración profundiza en el uso del primer sentido.

En conformidad con los planteamientos de los párrafos anteriores, en lo que sigue quisiera sostener que la imaginación también desempeña un papel central en La memoria, la historia, el olvido. Mi hipótesis es que esta facultad articula los distintos momentos de esta obra, fundamentalmente los que se relacionan con la fenomenología de la memoria y la epistemología de la historia. Asimismo, quisiera relativizar parcialmente la tesis de que a partir de Tiempo y narración Ricœur enfatiza el carácter sintético de la imaginación, mostrando que en la obra a la que me abocaré hay una fuerte presencia de la función libre. En ese sentido, simpatizo con la sugerencia de Hayden White de relacionar La memoria, la historia, el olvido directamente con Ideología y utopía. ${ }^{5}$ Con todo, también reconozco la fuerte presencia del primer sentido de imaginación, y sostengo que ambos sentidos funcionan de manera paralela, sin puntos de encuentro y articulación entre sí. Mi hipótesis es que el filósofo no cruza esos dos sentidos por su intención de deslindar lo que aquí describo como las funciones de cada una de esas imaginaciones: la función visualizante y la función no realizadora.

Dividiré el artículo en tres partes. En la primera analizaré el modo en que Ricœur rompe el vínculo tradicional entre memoria e imaginación y lo reestablece en términos de la imaginación productiva. En la segunda parte abordaré el problema de la ideología y de qué manera ésta y la imaginación se encuentran presentes en la relación entre memoria e

identidade prospectiva foi atenuada, em parte por conta da trajetória biográfica do autor, em parte, em função de uma mudança na temática predominante de sua pesquisa e em parte por uma alteração metodológica. Esta última razão é de especial interesse para mim, pois está mais relacionada à filosofia de Ricœur do que à sua biografia."

${ }^{4}$ Cfr. Taylor 2013, p. 130.

${ }^{5}$ Cfr. White 2007, p. 235. 
historia. Por último, discutiré si hay un lugar para la utopía en esta obra y, de haberlo, cuál sería la noción que la cumpliría.

\section{La impertinencia del vínculo intuitivo entre memoria e imaginación}

La relación entre memoria e imaginación se analiza en los dos capítulos que abren la primera parte. El capítulo inicial está dedicado a la dimensión cognitiva. Comienza con una disociación de la memoria y la imaginación y concluye con su rearticulación en la figura del reconocimiento. Por su parte, el segundo capítulo comienza con la tesis de que la memoria es una acción y, por lo tanto, que puede discutirse en el marco de la fenomenología del "hombre capaz". Sobre esta base se propone abordar la relación entre memoria e imaginación desde una perspectiva pragmática. ${ }^{6}$

Ricœur reconoce la referencia mutua entre memoria e imaginación, aunque considera que el modo en que la tradición filosófica la ha conceptualizado, desde los griegos hasta Hume pasando por Montaigne, Pascal y Spinoza, ha sido errónea. Según este relato, la memoria se subordinó a la imaginación y se la convirtió en una suerte de fuente degradada de conocimiento. Para determinar el origen de este error, el filósofo retrocede a su tratamiento fundacional en la Grecia clásica, donde descubre que la memoria se tematizó desde una problemática que comparte con la imaginación, es decir, desde la cuestión de la presencia de la ausencia, en lugar de tratarla desde su especificidad, esto es, desde la cuestión temporal: "el problema de la memoria desapareció en cuanto a su especificidad, aplastado por la problemática dominante, a saber, el problema de saber en qué compartimento se puede colocar al sofista" (Ricœur 2004, p. 28). Platón recurre a las metáforas del bloque de cera y a la alegoría del palomar para responder cómo es posible que la memoria sea la presencia de una ausencia. Por otra parte, su preocupación por la verdad del recuerdo como adecuación con la afección inicial debe considerarse un intento por deslindar a la memoria de la imaginación, cuyos destinos habían sido unidos con las metáforas anteriores. Incluso Aristóteles, reconocido por haber destacado la especificidad temporal de la memoria, sigue atado a la problemática

${ }^{6}$ Cfr. Ricour 2004, p. 46: "es a estas destrezas a las que, en la vasta panoplia de los usos del término 'memoria', aplicamos una de las acepciones admitidas de este término. [...] Tenemos, en primer lugar, las capacidades corporales y todas las modalidades del 'puedo' que recorro en mi propia fenomenología del 'hombre capaz': poder hablar, poder intervenir en el curso de las cosas, poder narrar, poder permitir que se me impute una acción como a su verdadero autor."

Diánoia, vol. LIX, no. 73 (noviembre de 2014). 
de la presencia de la ausencia. Justamente su interés en la presencia del recuerdo en el esfuerzo de la rememoración se debe a la necesidad de deslindar la memoria de la imaginación, reunidas por esta última problemática.

Una vez señalado el carácter erróneo de la asociación tradicional entre memoria e imaginación, Ricœur recurre a "las cosas mismas" para establecer cuáles son las bases de esta relación. Como lo expone el propio filósofo:

¿Qué necesidad existe de que, tras haber separado la imaginación de la memoria, haga falta asociarlas de un modo distinto del que habría regulado su disociación? En una palabra: ¿qué necesidad eidética demuestra la expresión recuerdo-imagen que no deja de atormentar a nuestra fenomenología de la memoria y que volverá con fuerza en el plano de la epistemología de la operación historiográfica con el nombre de representación historiadora del pasado? (Ricœur 2004, p. 67)

El planteamiento mismo de la pregunta en esta cita nos remite a los análisis fenomenológicos de la cuestión. Al igual que el resto de la tradición, Husserl consideró la imaginación un modo intencional afín a la percepción antes que a la significación. Desde este punto de partida, el filósofo alemán dedicó varios estudios a intentar deslindar la memoria de la imaginación. Uno de sus primeros enfoques se apoyó en la dimensión temporal de sendos objetos intencionados: la cosa recordada puede compararse con la fantasía en cuanto que lo recordado ya no existe, pero, en la medida en que ésta presenta nuevamente algo que ya ha sido, debe considerarse una modificación sui generis de la percepción. En cambio, en Ideas I el creador de la fenomenología se apoyó en la intersubjetividad como criterio de distinción entre memoria e imaginación: los recuerdos pertenecen a un mundo de la experiencia común, mientras que la imaginación se encuentra libre de esa experiencia por ser irreal. Pese a la extensión y profundidad de estos análisis, Ricœur no quedó satisfecho con sus resultados, pues no lograron responder a lo que, a sus ojos, es la pregunta central de esta temática: “¿Cómo explicar que el recuerdo vuelva bajo la forma de imagen y que la imaginación así movilizada venga a revestir formas que escapan a la función de lo irreal?" (Ricœur 2004, p. 74).

Ricœur se inclina por la propuesta bergsoniana de basar la articulación entre memoria e imaginación en el reconocimiento. Bergson distingue el recuerdo puro, también denominado recuerdo hábito, del recuerdo memoria. El primero es un recuerdo corporal, es decir, más actuado 
que representado, en el que desaparece el componente temporal. Un ejemplo paradigmático de este tipo de recuerdo es la lección estudiada, en la que se tiene en la mente la lección pero no el momento en que se la estudió. Lo propio del segundo tipo de recuerdo es lograr ver de nuevo lo vivido en el pasado. El recuerdo imagen se caracteriza como una forma intermedia, producto de la fusión de la memoria y la imaginación, "y era en el acto del reconocimiento donde se operaba esta fusión, señalada por el sentimiento de 'ya visto' " (Ricœur 2004, p. 75). Bergson describe este proceso a través de múltiples metáforas, pero básicamente todas apuntan a establecer la materialización o efectivización del recuerdo virtual a través de la imaginación. La reconstrucción imaginativa reconocida será la base de la fiabilidad, es decir, el ideal al que puede aspirar la memoria. ${ }^{7}$

Según este resumen, pareciera que el planteamiento de Bergson no se ajusta a la hipótesis señalada de que aquí la imaginación funciona como síntesis. En efecto, se afirma que en el reconocimiento se produce la síntesis y que la imaginación simplemente aporta una imagen. La primera observación pertinente es que las menciones a la imaginación en este pasaje son citas de Bergson, del que no se aclara que no tenga un concepto de imaginación reproductiva. La segunda tiene que ver con que, del hecho de que la imaginación productiva funcione como síntesis, no se sigue que excluya la posibilidad de hacernos ver. Como lo explica Kearney, "si la imaginación productiva se confinara a una innovación puramente verbal, dejaría de ser imaginación" (Kearney 1998, p. 151). La importancia del componente visualizante está presente en La memoria, la historia y el olvido, en donde, al menos en dos ocasiones, se señala la articulación entre la legibilidad y el ver-como (opsis): en este capítulo se hace al introducir con Aristóteles la función visualizante de la imaginación, y lo mismo en el capítulo tres de la segunda parte. ${ }^{8}$ Sin embargo, donde el filósofo aclara con mayor detenimiento este punto es, sin lugar a dudas, en La metáfora viva, donde incluso reconoce que el esquema en Kant "es un método para construir imágenes" (Ricœur 1980, p. 287). En esta obra, Ricœur explica la integración del

${ }^{7}$ Cfr. Ricœur 2004, p. 79: "es en el momento del reconocimiento, con el que concluye el esfuerzo de la rememoración, cuando se declara esta exigencia de verdad. Entonces sentimos y sabemos que algo sucedió, que algo tuvo lugar, que nos implicó como agentes, como pacientes, como testigos. Llamemos fidelidad a esta exigencia de verdad."

${ }^{8}$ Cfr. Ricœur 2004, 76 y p. 344: "Lo que, en otro lugar, llamábamos 'ficcionalización del discurso histórico', puede formularse de nuevo como entrecruzamiento de la legibilidad y la visibilidad en el seno de la representación historiadora.”

Diánoia, vol. LIX, no. 73 (noviembre de 2014). 
decir-como y el ver-como del siguiente modo: "Así, el 'ver como' juega el papel del esquema que une el concepto vacío y la impresión ciega; por su carácter de semipensamiento y semi-experiencia, une la luz del sentido con la plenitud de la imagen. De este modo, lo no-verbal y lo verbal se unen estrechamente en el seno de la función creadora de imágenes propia del lenguaje" (Ricœur 1980, pp. 289-290).

En la conclusión de la sección dedicada al reconocimiento, Ricœur distingue brevemente las dos funciones de la imaginación asociables a la distinción kantiana entre la imaginación sintética, recién mencionada, y la imaginación como variación libre. Así, respecto del recuerdo imagen, explica que "lleva, de alguna forma, el recuerdo a un área de presencia semejante a la de la percepción. Pero - y es aquí donde nos encontramos con la otra vertiente de la dificultad- no es una imagen cualquiera la que se moviliza así. Al contrario de la función no realizadora que culmina en la ficción exiliada en la exterioridad de toda la realidad, lo que se exalta es su función visualizadora, su modo de dar a ver" (Ricœur 2004, pp. 75-76). Tenemos así que la imaginación vuelta a vincular con la memoria a través del reconocimiento de Bergson tiene una función visualizadora, diferente de la función no realizadora, que se vincularía con la función libre de la imaginación. De este modo, las consideraciones posteriores apuntan a lo que denomina la trampa de lo imaginario, y que es la patologización de las funciones de la imaginación conducentes a la alucinación. ${ }^{9}$ Esta patologización termina por incidir en la fiabilidad mnémica.

\section{3. ¿Puede estar la imaginación entre la memoria y la historia?}

El tratamiento de los usos y abusos de la memoria en el capítulo siguiente busca mostrar cómo se produce este desplazamiento hacia la patologización mnémica. En el caso de la memoria artificial alude a la función visualizante, en cuanto que los abusos de la memoria natural están ligados con la función no realizadora de la imaginación. El tratamiento de los usos y abusos de la memoria artificial es meramente secundario en el marco de esta obra, fundamentalmente porque sus efectos se limitan a una adulteración de la función mnémica y no inciden en la capacidad del ser humano. Por el contrario, se enfatiza el carácter activo de esta memoria en oposición a la pasividad que caracteriza a los abusos de la memoria natural. En líneas generales, en esta sección se tematiza el accionar de la memoria para fijar artificialmente

${ }^{9}$ Cfr. Ricœur 2004, p. 78. 
los conocimientos y el proceso histórico que condujo del "uso" al "abuso", es decir, el proceso por el que la imaginación terminó por tener prioridad sobre la memorización: "la mnemotecnia que se aplica aquí es en honor a la imaginación, de la que la memoria se convierte en el anexo" (Ricœur 2004, p. 88). La mnemotécnica tiene como objetivo fijar los recuerdos a través de una imagen. Así, se explica que "se trata de 'colocar' las imágenes en lugares, pero estos lugares son los astros, y estas imágenes, las 'sombras' [...] en que consisten los objetos y los acontecimientos del mundo inferior" (Ricœur 2004, p. 91). Finalmente, "la sobreestimación que el ars memoriae hace de las imágenes y de los lugares tiene como precio el descuido del acontecimiento que asombra y sorprende" (Ricœur 2004, p. 93).

De las tres manifestaciones de los abusos de la memoria natural (y el olvido) — la memoria impedida, la manipulada y la obligada-, la que nos interesa tratar aquí es la segunda. No es que la referencia al psicoanálisis en el tratamiento de la memoria impedida no tenga vínculo alguno con la imaginación. De hecho, en las exploraciones que Ricœur realizó durante la década de los setenta de la obra de Freud reconoce la importancia de la imaginación productiva. ${ }^{10}$ Sin embargo, en la obra que analizo las consideraciones en torno al psicoanálisis se restringen a la posibilidad de aplicar las categorías metapsicológicas a lo colectivo, dejando de lado la cuestión de la imaginación. Por lo tanto, la reconstrucción de esta problemática en el marco conceptual que me interesa excedería el objetivo de este artículo.

En lo que respecta específicamente a la memoria manipulada, su vínculo con la imaginación surge del análisis de la manipulación de la memoria por medio de la ideología. En opinión de Ricœur, la manipulación ideológica es una respuesta a los problemas de identidad, tanto personal como colectiva, debidos al paso del tiempo, al contacto con el otro o a la violencia fundadora. En La memoria, la historia, el olvido no hay un estudio original de la ideología, sino que se retoman las consideraciones de Ideología y utopía ${ }^{11}$ En aquella obra se enfatiza que ni la ideología ni la utopía son por sí mismas negativas. ${ }^{12}$ Cada una de

${ }^{10}$ Cfr. Ricœur 1990, p. 17 y Kearney 1998, p. 144.

${ }^{11}$ Si bien en la tercera parte de Del texto a la acción Ricœur reúne algunas de las consideraciones hechas en Ideología y utopía, en Ricœur 2004, pp. 110-115, sólo mencionará la última de ellas.

${ }^{12}$ De hecho, en su distinción de los tres niveles de la ideología se considera que toda mediación simbólica es ideológica. Esto significa que el ser humano, en tanto que ser simbólico, es constitutivamente ideológico y que, por consiguiente, resulta imposible su eliminación. Cfr. Ricœur 1986, p. 314: "la ideología es un fenómeno 
ellas tiene una función que le es propia (la ideología es integradora y la utopía es proyectiva y desenmascaradora) y su patologización se debe, en su opinión, a la concepción misma de imaginación como proceso con la que se encuentran asociadas: "si la imaginación es un proceso antes que un estado, se vuelve comprensible que a cada dirección del proceso de la imaginación corresponde una disfunción específica." (Ricœur 1986, p. 235). Mientras que la ideología tiene a la disimulación y a la distorsión como disfunciones propias, la función excéntrica de la utopía conduce a la esquizofrenia. Ricœur mantiene la distinción en tres niveles con la que había presentado a la ideología treinta años antes. El nivel más profundo consiste en la mediación simbólica entre las motivaciones de la acción humana y sus estructuras genéticas de comportamiento; el segundo es la legitimación del poder; por último se encuentra el sistema de integración basado en la imagen o representación que tenemos de nosotros. El filósofo sostiene aún que el abuso se produce en el nivel de la legitimación del poder. Según explica, "la ideología, en definitiva, gira en torno al poder. [...] La ideología, se puede suponer, tiene lugar precisamente en el resquicio entre el requerimiento de legitimidad que emana de un sistema de autoridad y nuestra respuesta en términos de creencia. La ideología añadiría una especie de plusvalía a nuestra creencia espontánea, gracias a lo cual ésta podría cumplir con los requerimientos de la autoridad." (Ricœur 2004, p. 113).

La novedad respecto de las obras de los ochenta es que las consideraciones en torno a la ideología y la utopía se concretizan y las consideraciones políticas se articulan con la labor del historiador. En efecto, Ricœur sostiene que el poder recurre a terceros para legitimarse: "La dominación, como hemos visto, no se limita a la coacción física. Hasta el tirano necesita un teórico, un sofista, para proporcionar un intermediario a su empresa de seducción y de intimidación." (Ricœur 2004, p. 115). Aunque en estas consideraciones no se menciona explícitamente a la figura del historiador como el manipulador, dicha conclusión se desprende de las referencias al análisis de Marin acerca del uso de la imaginación por parte del historiador para seducir al poder:

en efecto, el "Projet de l'histoire de Louis XIV" es un texto bastante particular en cuanto que presenta ante el lector las estratagemas de la historia todavía por escribir con el propósito, apenas disimulado, de hacer caer en insuperable de la existencia social, en la medida en que la realidad social posee desde siempre una constitución simbólica y comporta una interpretación, en las imágenes y representaciones, del vínculo social mismo." 
su trampa, que no es otra que la subvención real, al destinatario último del escrito, el rey. La estratagema de la escritura puesta al descubierto así se reduce al uso astuto de los prestigios de la imagen puesto al servicio de la alabanza. (Ricœur 2004, p. 348)

Por si fuera poco, Ricœur concluye ampliando el alcance de las investigaciones históricas de Marin a las prácticas sociales contemporáneas con sus consideraciones acerca de la grandeza y la posibilidad de una suerte de discursos históricos reprobatorios ante acontecimientos límite. Siguiendo a Marin, Ricœur introduce la figura de Pascal para recordarnos sobre la importancia vital de la imaginación en este proceso legitimante del poder. En efecto, "la imaginación dispone de todo; crea la belleza, la justicia y la felicidad que es el todo del mundo." (Ricœur, p. 355).

La configuración narrativa posee una importancia fundamental en este proceso de manipulación ideológica y elaboración de una "historia oficial" que pueda enseñarse a todos los gobernados y legitimar al poder de turno, al modelar tanto la estructura de la acción como la identidad de los protagonistas. El filósofo francés aborda esta temática en el tratamiento de la manipulación del olvido, contrafigura de la memoria manipulada. Allí, se explica, "fue posible la ideologización de la memoria gracias a los recursos de variación que ofrece el trabajo de configuración narrativa. Las estrategias del olvido se injertan directamente en ese trabajo de configuración: siempre se puede narrar de otro modo suprimiendo, desplazando los momentos de énfasis, refigurando de modo diferente a los protagonistas de la acción al mismo tiempo que los contornos de la misma." (Ricœur 2004, p. 572). Pese a no haber una referencia explícita a la imaginación en el proceso de la configuración, esta relación fue extensamente desarrollada en el primer tomo de Tiempo y narración al referirse a la mimesis II. Allí Ricœur compara el papel de la imaginación en la producción configurante con el esquematismo kantiano. Así como en Kant la imaginación sintetiza en el esquematismo al entendimiento y la intuición, "la construcción de la trama engendra igualmente la inteligibilidad mixta entre lo que hemos llamado la punta, el tema, el 'pensamiento' de la historia narrada, y la presentación intuitiva de las circunstancias, de los caracteres, de los episodios y de los cambios de fortuna que crean el desenlace. Así, se puede hablar del esquematismo de la función narrativa." (Ricœur 1995, p. 135). 
4. El papel de la utopía en La memoria, la historia, el olvido

Los usos y abusos de la memoria natural presentan una memoria manipulada pasivamente por la ideología y que pareciera incapaz de reaccionar. En Tiempo y narración Ricœur coincidía con Gadamer en la posibilidad de romper con la tradición. En efecto,

con la idea de investigación, se afirma un momento crítico, ciertamente secundario pero ineluctable, que llamo relación de distanciación, y que designa desde ahora el lugar vacío de la crítica a las ideologías de la que hablaremos dentro de poco. Son esencialmente las vicisitudes de la tradición $-\mathrm{O}$, mejor dicho, de las tradiciones rivales a las que pertenecemos en una sociedad y en una cultura pluralistas-, sus crisis internas, sus interrupciones, sus reintempretaciones dramáticas, sus cismas, lo que introducen en la tradición misma, en cuanto instancia de verdad, una polaridad entre familiaridad y extrancidad. (Ricœur 1996, p. 965)

A diferencia de Tiempo y narración, en La memoria, la historia, el olvido se introduce una cesura ontológica y epistémica entre el acontecimiento histórico y el hecho histórico, impidiendo la aplicación directa del esquema anterior. El acontecimiento histórico es el referente del discurso histórico, lo que ocurrió en el pasado. El hecho histórico, en cambio, es su reconstrucción proposicional. De esta manera, si uno quisiera ser preciso al hablar debería decir: "el hecho de que esto aconteció". El filósofo caracteriza esta distinción del siguiente modo: "el hecho en cuanto 'la cosa dicha', el qué del discurso histórico, del acontecimiento en cuanto 'la cosa de la que se habla', el 'a propósito de qué' es el discurso histórico." (Ricœur 2004, p. 234).

Detenerme a evaluar la totalidad de cambios a los que conduce esta distinción excedería mis objetivos en este trabajo. Mencionaré simplemente que la memoria está asociada al acontecimiento histórico y, como tal, permanece atada al pasado. En la medida en que el acontecimiento no es una proposición, la memoria no es ni verdadera ni falsa, sino que tiene que aspirar a la fidelidad. Mientras que todos estos elementos ponen de manifiesto la pertenencia de la memoria al pasado, la historia se encuentra constitutivamente distanciada respecto de los acontecimientos pasados. Esta ruptura la produce el archivista al asentar de manera escrita los testimonios del pasado. En la medida en que la historia construye los hechos históricos, ella sí tiene una posición crítica respecto del pasado. Estos dos modos de vincularse con el pasado crean una relación particular entre la memoria y la historia, que Ricœur resume del siguiente modo: 
Llegados a este punto extremo de reducción historiográfica de la memoria, dejamos oír la protesta en la que se refugia el poder de atestación de la memoria sobre el pasado. La historia puede ampliar, completar, corregir, incluso refutar, el testimonio de la memoria sobre el pasado. ¿Por qué? Porque pensamos que la memoria sigue siendo el guardián de la última dialéctica constitutiva de la paseidad del pasado, a saber: la relación entre el 'ya no' que señala su carácter terminado, abolido, superado, y el 'sido' que destina su carácter originario y, en este sentido, indestructible. Algo así sucedió realmente: ésta es la creencia antipredicativa —e, incluso, prenarrativa - sobre la que descansa el reconocimiento de las imágenes del pasado y el testimonio oral. [...] Esta protesta, que alimenta la atestación, es de la naturaleza de la creencia: puede ser discutida, pero no refutada. (Ricœur 2004, p. 637)

En pocas palabras, la memoria es incapaz de "distanciarse" del pasado para explicitar la ideología que está en la base de su vínculo con el pasado. Por su parte, el historiador es aquel que se encuentra en condiciones de manipular la memoria, pero también es capaz de denunciar dicha manipulación. Justamente a propósito de las investigaciones de Marin, Ricœur reconoce que "Lo sorprendente sigue siendo que el autor del proyecto de historia haya intentado desmontar la trampa enunciándola - para dicha de la historiografía contemporánea" (Ricœur 2004, p. 350). La pregunta que surge a continuación es ¿desde dónde lleva a cabo la historia su crítica a las ideologías?

Ya en Tiempo y narración Ricœur había señalado lo absurda que resultaba la posibilidad de tomar a la realidad o al saber absoluto como lugares desde donde criticar a las ideologías, y afirmó la necesidad de hacerlo desde otro proyecto o interés. ${ }^{13}$ Si nos remitimos a los planteamientos de Ideología y utopía, la crítica a las ideologías debe hacerse desde una determinada utopía: "es también mi convicción: la única manera de salir del círculo en el cual la ideología nos conduce, es asumir una utopía, declararla y juzgar la ideología desde este punto de vista. Porque el observador absoluto es imposible, no puede ser que alguien situado en el proceso mismo quien asuma la responsabilidad del juicio." (Ricœur 1997, p. 231). Curiosamente, en La memoria, la historia, el olvido no hay un tratamiento explícito sobre la utopía. La única referencia que se hace de este concepto es para contraponerlo al carácter inconfesable de la ideología. ${ }^{14}$ Sin embargo, soy de la opinión de que el hecho de que no se teorice acerca de la utopía no significa que esté ausente de

${ }^{13}$ Cfr. Ricœur 1996, p. 967.

${ }^{14}$ Cfr. Ricœur 2004, p. 112. 
esta obra, sino que, como quisiera mostrar a continuación, posee una gran importancia operativa. Para hacerlo, comenzaré por señalar cuál es la utopía en esta obra, y luego indicaré de qué manera organiza la investigación.

Para determinar cuál es la utopía operativa, debemos retrotraernos al tercer tomo de Tiempo y narración, en el que Ricœur plantea algunas características que deben poseer las utopías para funcionar como tales. Allí señala que, por una parte, éstas deben estar ancladas en la experiencia, es decir, deben ser determinadas y relativamente modestas para generar compromiso y, por la otra, deben alcanzar a la humanidad entera como singular colectivo. ${ }^{15}$ Esta caracterización de una utopía deseable nos conduce a lo que consideramos la utopía que guía esta obra, a saber, la memoria feliz. En efecto, la memoria feliz cumple con las dos condiciones mencionadas: es un ideal relativamente modesto, anclado en la experiencia, y también alcanza a la humanidad como singular colectivo.

La memoria feliz se caracteriza como "la estrella guía de toda la fenomenología de la memoria" (Ricœur 2004, p. 633). En líneas generales, funciona de manera análoga a la utopía, en tanto que manifiesta las potencialidades del ser humano y lo que puede llegar a alcanzar. La memoria feliz es un ideal que se contrapone a la memoria impedida y que lleva a que el historiador no sea un mero teórico, sino también un actor social, que hace las veces de psicólogo social y crítico de las ideologías. La memoria feliz incorpora asimismo el componente rupturista de pensar de otro modo lo social, lo cual es una característica propia de la utopía. Hay una suerte de relación circular entre la memoria feliz como prescripción práctica y la fenomenología de la memoria en su calidad de descripción eidética del fenómeno mnémico. Por una parte, la memoria feliz surge del análisis fenomenológico de la memoria, según el "ritmo ternario": describir, narrar, prescribir. ${ }^{16}$ Por la otra, la memoria feliz se constituye en una suerte de norte hacia donde deben tender los análisis fenomenológicos de la memoria. Como lo explica el filósofo: "A mi modo de ver, lo que importa es abordar la descripción de los fenómenos mnemónicos desde el punto de vista de las capacidades de las que ellos constituyen la efectuación 'feliz"' (Ricœur 2004, p. 40). La memoria feliz es el motivo por el que Ricœur retoma la oposición de Todorov entre memoria literal y ejemplar, sin coincidir totalmente con su tesis acerca de que la misión del historiador sea seleccionar hechos

${ }^{15}$ Cfr. Ricœur 1996, pp. 952-953.

${ }^{16}$ Cfr. Ricœur 1996b, p. XXXIII. 
con miras al bien y no a la verdad, planteada hacia el final de la sección dedicada a la memoria manipulada. ${ }^{17}$ Ella también debe servir al historiador como guía para resolver los abusos de la memoria impedida y la memoria manipulada. Por último, la memoria feliz se constituye en el marco en que el filósofo compara el olvido y el perdón, para inclinarse finalmente por este último. ${ }^{18}$

\section{Acerca de la relación entre memoria e historia}

A lo largo de estas páginas he establecido la importancia de la imaginación productiva en La memoria, la historia, el olvido. En la primera sección mostré de qué manera Ricœur deslinda la asociación tradicional entre memoria e imaginación reproductiva, para luego establecer el vínculo nuevamente pero pensándolo desde una imaginación productiva. Con el fin de construir este nexo, el filósofo francés rescata el reconocimiento bergsoniano como punto de síntesis entre la imagen y el recuerdo. En la segunda sección puse de manifiesto que el planteamiento de la memoria manipulada se basa en el concepto de imaginación productiva libre, más ligada con la imaginación tratada por Kant en la Crítica del juicio. Por su parte, la crítica a las ideologías propuesta por el filósofo francés me llevó a discutir la cuestión de la contraparte de la ideología, es decir, la utopía. Aunque reconocí que este término apenas si se menciona en esta obra, y sólo de manera tangencial, sostuve que el concepto de memoria feliz cumple con las condiciones que el filósofo había impuesto en Tiempo y narración a una utopía responsable: ser accesible y dirigirse a la humanidad entera. En el curso de estas investigaciones, la memoria feliz guiaba los lineamientos de los análisis teóricos acerca de la memoria, y era una pauta de cambio para enfrentar los abusos de la memoria natural.

En síntesis, sostuve que en la obra en cuestión Ricœur trabaja con las dos acepciones de imaginación productiva propuestas por Kant: la sintética y la libre. En ese sentido, he relativizado la posición de G. Taylor, para quien en obras como Ideología y utopía se priorizaba una imaginación libre, en tanto que, a partir de Tiempo y narración, acaba por tener preponderancia la función sintética. Cada una de estas funciones operaba de manera paralela en niveles discursivos diferentes: la imaginación sintética en el nivel de la fenomenología de la memoria, reuniendo en el reconocimiento una imagen a un recuerdo puro; la

${ }^{17}$ Cfr. Ricœur 2004, p. 117.

${ }^{18}$ Cfr. Ricœur 2004, pp. 531 y ss.

Diánoia, vol. LIX, no. 73 (noviembre de 2014). 
imaginación libre, por su parte, en el proceso "político" de la manipulación mnémica a través de la ideología y la crítica a esta ideología por medio de la utopía de la memoria feliz.

A manera de cierre quisiera destacar el modo en que la imaginación clausura el abismo abierto entre la memoria y la historia. Mencioné de paso que la distinción entre acontecimiento y hecho histórico establecía una cesura ontológica y epistémica entre la memoria y la historia. El archivista produce este corte cuando asienta de manera escrita los testimonios orales. La cuestión es que si este corte se mantuviera a lo largo de toda la obra, la memoria y la historia funcionarían de manera paralela, no pudiendo así la memoria ser manipulada por medio de configuraciones históricas de mala fe ni salvada de dicha manipulación por medio de la crítica a las ideologías. Tanto en el análisis del reconocimiento mnémico como de la representación histórica, el filósofo recuerda lo ya planteado en La metáfora viva, a saber, que el decir como proporcionado por la imaginación productiva aporta una imagen, nos permite un ver como (opsis). "En este punto, no se puede dejar de evocar el último componente del mythos que, según la Poética de Aristóteles, estructura la configuración de la tragedia y la epopeya, a saber, la opsis, de la que se dice que consiste en 'poner ante los ojos', en mostrar, en hacer ver" (Ricœur, 2004, p. 76). Gracias a que la imaginación tiene este doble componente, la memoria y la historia logran interactuar entre sí.

\section{BIBLIOGRAFÍA}

Kearney, R., 1998, Poetics of Imagining: Modern to Post-Modern, Edinburgh University Press, Edimburgo.

Revault d'Allonnes, Myriam, 1986, "Avant-propos à l'édition française" en P. Ricour, Lidéologie et l'utopie, Seuil, París.

Ricœur, P., 1980, La metáfora viva, Ediciones Cristiandad, Madrid.

—_, 1986, Du texte à l'action. Essais d'herméneutique II, Seuil, París.

— 1990, Freud: una interpretación de la cultura, Siglo XXI, México.

— 1995 , Tiempo y narración I. Configuración del tiempo en el relato histórico, Siglo XXI, México/Buenos Aires.

—, 1996, Tiempo y narración III. El tiempo narrado, Siglo XXI, México/Buenos Aires.

—_, 1996b, Sí mismo como otro, Siglo XXI, México/Buenos Aires.

— 1997 , Lidéologie et l'utopie, Seuil, París.

—_ 2004, La memoria, la historia, el olvido, Fondo de Cultura Económica, Buenos Aires.

Taylor, G., 2013, "Identidade prospective", en Nascimento, Fernando y Walter Salles (comps.), Paul Ricœur. Ética, Identidade e Reconhecimento, Loyola, Río de Janeiro. 
_ 2006, "Ricœur's Philosophy of Imagination" en Journal of French Philosophy, vol. 16, n. 1-2, pp. 93-104.

White, H., 2007, "Guilty of History? La longue durée of Paul Ricœur", en History and Theory 46, pp. 233-251.

Recibido el 9 de octubre de 2013; aceptado el 27 de marzo de 2014. 